\title{
Adult Learning: The Importance of Knowing Your Student Profile
}

\author{
Dr Alison Watson
}

Arden University

\begin{abstract}
The manuscript focuses on 'continuing education' within the adult higher education sector. The research relates to a newly-chartered UK private university. The issue which the university is encountering relates specifically to its newness as an adult education provider and the consequence of being relatively unknown in the higher education market, hence the need for market research relating to student recruitment. The main objective of the current research is therefore to identify potentially profitable adult segments on which to focus the recruitment processes such as: Digital Achievers (DA), Constrained Career Strivers (CCS), Practical Upskillers (PU) and Disengaged Learners (DL). Initial findings indicate that students in the DA and CCS segments are performing reasonably successfully, as expected. However, the PU and DL students are underperforming due to the university's limited knowledge of the students' profiles. These latter segments mainly consist of students from Widening Access and Participation backgrounds. Consequently, a mixed methods approach is being undertaken in order to understand why these students selected the university, and also the strategic decisions that the organisation's management has made regarding student recruitment. Research recommendations include reviewing the four segments in order to identify specific student learning needs. Initial findings suggest targeting the DL group and developing outreach programmes, building resilience into the curricula to help the PU, DL and CCS to transition and become effective continued learners; and finally, develop the DA market.
\end{abstract}

Keywords: Access; Needs; Outreach; Resilience; Segmentation 